\title{
Spontaneous deletions of drug-resistance determinants from Salmonella typhimurium in Escherichia coli
}

\author{
S. ROY and M. CHAKRAVORTY
}

Molecular Biology Unit, Department of Biochemistry, Institute of Medical Sciences, Banaras Hindu University, Varanasi-221005, India

\begin{abstract}
Summary. Plasmids isolated from two different clinical isolates of Salmonella typhimurium, both resistant to the antibiotics ampicillin, tetracycline, streptomycin and chloramphenicol, were used to transform Escherichia coli. Segregation of antibiotic-resistance determinants occurred in both cases. Analysis of plasmids from one set of segregants by DNA-DNA hybridisation indicated that the segregation was due to precise deletions in the transforming plasmid.
\end{abstract}

\section{Introduction}

One aspect of R-plasmid-mediated spread of antibiotic resistance amongst enterobacteria which has remained enigmatic is the mechanism or mechanisms by which $\mathbf{R}$ factors evolve during their dissemination. Although the emergence of multiresistant Salmonella typhimurium in Britain correlated with the prophylactic use of antibiotics in cattle feed, no such obvious reason can be adduced to explain the appearance of plasmid-borne multiresistance in $S$. typhimurium strains that have caused several outbreaks of human salmonellosis in India in recent years (Sood and Basu, 1983). One attractive hypothesis is that $\mathbf{R}$ plasmids are acquired from a repository in commensal bacteria in response to antibiotic therapy, as has been suggested to have caused the appearance of antibiotic resistant $S$. typhi (Datta et al., 1981; Threlfall et al., 1982). Threlfall et al. (1982), however, found that the spectrum of resistances encoded in the plasmid acquired by $S$. typhi during antibiotic therapy was different from that of a multi-resistant $S$. typhimurium strain which was co-isolated. They suggested that intestinal enterobacteria may have been the sources of $\mathbf{R}$ factors, a not unreasonable suggestion in view of the frequently reported opportunist infections by antibiotic-resistant Escherichia coli (Grüneberg and Bendall, 1979; Christie, 1980; Gross et al., 1983) and the well documented spread of R plasmids across generic barriers (Datta et al., 1980; Tompkins et al., 1980). In the present report we describe experiments to show whether transfer

Received 26 Jul. 1985; revised version accepted 13 Nov. 1985. of an R plasmid from a multi-resistant isolate of $S$. typhimurium into $E$. coli $\mathrm{K} 12$ may result in plasmid instability leading to an altered plasmid genotype.

\section{Materials and methods}

\section{Bacterial strains}

S. typhimurium strains 993 and 16408 were clinical isolates obtained from Professor Srinivasan, Department of Microbiology, All India Institute of Medical Sciences, New Delhi. E. coli K12 strain ED $8654\left(m^{-} t^{-} \mathrm{rk}^{-} \mathrm{mk}^{+}\right.$ supE trp $\mathrm{R}^{-}$) was obtained from Dr D. Botstein, Massachusets Institute of Technology, Cambridge, MA, USA and E. coli $\mathrm{K} 12$ strain $\mathrm{DH} 1$ (endoI $\mathrm{I}^{-} r e c \mathrm{~A}^{-} r \mathrm{k}^{-} m \mathrm{k}^{-} \mathrm{Nal}^{\mathrm{R}}$ ) from Dr B. Hohn, Friedrich Miescher Institute, Basel, Switzerland.

\section{Plasmid DNA preparation}

Cleared lysates were prepared from bacteria as described by Clewell and Helinski (1970). Protein was removed from the lysates by two extractions with phenol saturated with Tris-EDTA (TE) (0.01 м Tris- $\mathrm{HCl}, p \mathrm{H} \mathrm{7.6}$; $0.001 \mathrm{M}$ EDTA) followed by two extractions with chloroform. The DNAs present in the lysate were precipitated with ethanol and dissolved in TE before electrophoresis or transformation.

\section{Transformation}

E. coli strain ED 8654 was transformed with $S$. typhimurium plasmid DNA, as described by Maniatis et al. (1982). Transformants were selected on tryptone-agar plates containing ampicillin $50 \mu \mathrm{g} / \mathrm{ml}$, streptomycin 50 
$\mu \mathrm{g} / \mathrm{ml}$, tetracycline $20 \mu \mathrm{g} / \mathrm{ml}$ or chloramphenicol $20 \mu \mathrm{g} /$ $\mathrm{ml}$.

\section{Probe DNAs}

Plasmids pMS6 and pMS7 were radiolabelled with [ $\left.\alpha^{32} \mathrm{P}\right] \mathrm{dCTP}$ by nick-translation (Maniatis et al., 1982).

\section{Southern blot hybridisation}

Plasmid DNAs were separated by electrophoresis in $0.7 \%$ agarose gels at $3 \mathrm{~V} / \mathrm{cm}$ for $5 \mathrm{~h}$ and, after denaturation, transferred on to nitrocellulose filters and hybridised with ${ }^{32} \mathrm{P}$-labelled probe for $18 \mathrm{~h}$ (Maniatis et al., 1982). The filters were washed at room temperature with double strength SSC (SSC contained $0 \cdot 15 \mathrm{M} \mathrm{NaCl}$, $0.01 \mathrm{M}$ sodium citrate), containing sodium dodecyl sulphate $0.1 \%(2 \times \mathrm{SSC}, 0.1 \%$ SDS $)$ followed by washing with $2 \times \mathrm{SSC}$. $0 \cdot 1 \%$ SDS at $68^{\circ} \mathrm{C}$ for $2 \mathrm{~h}$ to increase the stringency of hybridisation. The filters were dried and autoradiographs prepared by exposing the dried filters to $\mathrm{X}$-ray film for $24 \mathrm{~h}$ at $-20 \mathrm{C}$ before the films were developed.

\section{Results}

S. typhimurium strains 993 and 16408, both resistant to ampicillin, tetracycline, streptomycin and chloramphenicol, harboured plasmids (fig. 1). S. typhimurium strain 16408 (lane 2) harboured a single plasmid of mol. wt $12 \times 10^{6}$. S. typhimurium strain 993 (lane 1) harboured two plasmids-a larger one similar in size to the plasmid of strain 16408 and a smaller one of mol. wt $5.8 \times 10^{6}$. The two leading bands in lane 1 represent the covalently closed circular and open circular forms of the smaller plasmid.

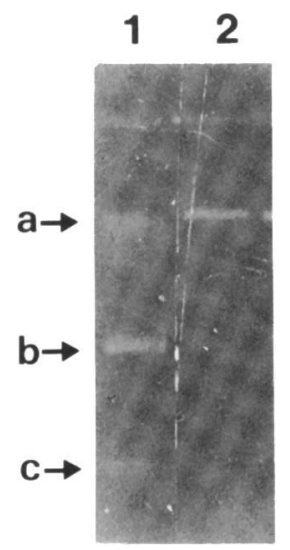

Fig. 1. Agarose gel electrophoresis of plasmids isolated from $S$. typhimurium strains 993 (lane 1) and 16408 (lane 2), (a) large plasmids (mol. wt $12 \times 10^{6}$ ), (b) small plasmid (mol. wt $5.8 \times 10^{6}$ ), covalently closed circular from, (c) small plasmid open circular form.
Plasmid preparations from $S$. typhimurium strains 993 and 16408 were used separately to transform $E$. coli $\mathrm{K} 12 \mathrm{ED} 8654$. The transformants were selected on tryptone-agar plates containing ampicillin, tetracycline, streptomycin or chloramphenicol. The transformants obtained with the plasmid from $S$. typhimurium strain 16408, which harboured a single plasmid, were expected to be resistant to all four antibiotics irrespective of the selecting antibiotic, whereas the segregation of resistance determinants in transformants with $S$. typhimurium strain 993 plasmid DNA preparations was expected to indicate the distribution of resistance determinants between the two plasmids present in this strain. Most transformants with plasmids from both $S$. typhimurium strains were resistant to all four antibiotics, indicating that, in both cases, all four resistance determinants were present on the same replicon. However, a considerable proportion of the transformants $(20.4 \%$ and $32 \cdot 2 \%$ respectively) showed segegation of resistance determinants (tables I and II). Although many of the possible combinations of resistance phenotypes were observed, there was a marked predominance of those that retained both ampicillin and tetracycline resistance. With transformation by $S$. typhimurium strain 993 plasmid DNA, resistance to all four antibiotics may have been the result of co-transformation with two plasmids carrying different resistance determinants, but no clear-cut segregation pattern consistent with the resistance determinants being present on different replicons was observed (table II). Thus, as well as the predominant phenotype, ApTcSmCp (resistance to ampicillin, tetracycline, streptomycin and chloramphenicol), various phentoypes (Ap, ApTc, ApTcCp, ApSmCp, SmCp and $\mathrm{Sm}$ ) were observed amongst the segregants.

Agarose gel electrophoresis of plasmids isolated from different transformants revealed heterogeneity in their sizes (fig. 2). MS5 (Sm; lane 2), MS6 (SmCp; lane 3), MS10 (Tc; lane 4) and MS7 (Ap; lane 5), harboured plasmids of mol. wts $\left(10^{6}\right) 1.7$, $2 \cdot 4,0 \cdot 8$ and $2 \cdot 8$ respectively. It appeared that part of the original plasmid had been deleted in the segregants, the heterogeneity in sizes resulting from the deletions being of different sizes. To confirm that the loss of resistance determinants also resulted from these deletions in the transforming plasmid, plasmids from transformants $E$. coli MS6 (SmCp; fig. 2, lane 3) and $E$. coli MS7 (Ap; lane 5) obtained by transformation of $E$. coli ED 8654 with $S$. typhimurium strain 993 plasmid DNA, were radiolabelled by nick-translation and plasmid preparations from several segregants obtained after transformation with $S$. typhimurium strain 993 
Table 1. Phenotypes of $E$. coli transformants obtained by transforming $E$. coli ED 8654 with the plasmid DNA from $S$. typhimurium strain 16408.

\begin{tabular}{lcccccc}
\hline & \multicolumn{3}{c}{ Number of transformant colonies of each phenotype obtained } \\
\cline { 2 - 7 } $\begin{array}{l}\text { Selecting } \\
\text { antibiotic }\end{array}$ & ApTcCpSm & ApTcSm & ApTcCp & ApCpSm & ApTc & Sm \\
\hline Ampicillin & 29 & 1 & 0 & 1 & 5 & 0 \\
Tetracycline & 23 & 0 & 0 & 0 & 14 & 0 \\
Chloramphenicol & 24 & 0 & 1 & 0 & 0 & 0 \\
Streptomycin & 14 & 0 & 0 & 0 & 0 & 1 \\
\hline
\end{tabular}

$\mathrm{Ap}, \mathrm{Tc}, \mathrm{Cp}, \mathrm{Sm}=$ resistance to ampicillin, tetracycline, chloramphenicol and streptomycin respectively.

Table II. Phenotype of E. coli transformants obtained by transforming E. coli ED 8654 with plasmid DNA from S. typhimurium strain 993

\begin{tabular}{lcccccccc} 
& \multicolumn{6}{c}{ Number of transformant colonies of each phenotype obtained } \\
\cline { 2 - 8 } $\begin{array}{l}\text { Selecting } \\
\text { antibiotic }\end{array}$ & ApTcCpSm & ApTcSm & ApTcCp & ApCpSm & ApTc & CpSm & Ap & Sm \\
\hline Ampicillin & 20 & 0 & 1 & 1 & 4 & 0 & 24 & 0 \\
Tetracycline & 21 & 1 & 2 & 0 & 2 & 0 & 0 & 0 \\
Chloramphenicol & 29 & 0 & 3 & 0 & 0 & 0 & 0 & 0 \\
Streptomycin & 28 & 0 & 0 & 0 & 0 & 1 & 0 & 9 \\
\hline
\end{tabular}

Abbreviations: see footnote to table I.

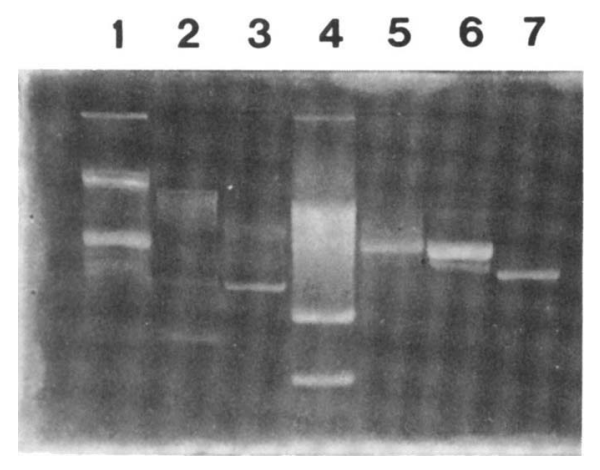

Fig. 2. Agarose gel electrophoresis of plasmids isolated from $S$. typhimurium strain 993 (lane 1) and from $E$. coli transformants MS5 (lane 2), MS6 (lane 3), MS10 (lane 4) and MS7 (lane 5). Lanes 6 and 7 contain plasmids pBR322 and ColE1 respectively.

plasmid DNA were probed with the labelled DNAs.

Plasmid preparations from $E$. coli transformants MS5 (Sm; fig. 2, lane 2), MS6 (SmCp; lane 3), MS10 (Tc; lane 4) and MS7 (Ap; lane 5) were electrophoresed on two identical $0.7 \%$ agarose gels with a plasmid preparation from the parent S. typhimurium strain 993 (fig. 2, lane 1). Plasmids pBR322 (Bolivar and Backman, 1979), bearing ampicillin

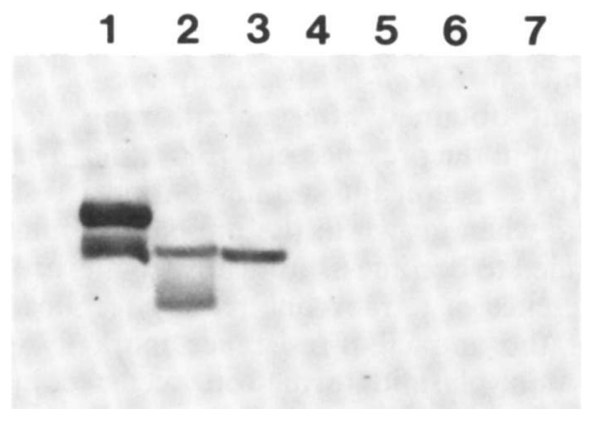

Fig. 3. Hybridisation of labelled DNA pMS6 (probe) with a Southern blot of the gel shown in fig. 2 .

and tetracycline resistance determinants, and ColE1, were also run on the same gel to serve as positive and negative controls respectively (fig. 2, lanes 6 and 7). The DNAs in the two gels were transferred to nitrocellulose (Southern blot) and the blots were hybridised separately with radiolabelled pMS6 (the plasmid from $E$. coli MS6) and pMS7 (the plasmid from $E$. coli MS7) used at a dose of c. $10^{6} \mathrm{cpm} / \mathrm{blot}$ in stringent conditions, and autoradiographed (figs 3 and 4). As expected, pMS6 


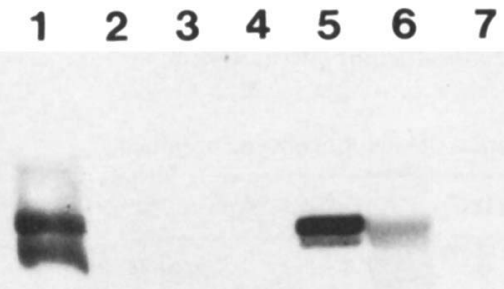

Fig. 4. Hybridisation of labelled DNA pMS7 (probe) with a Southern blot of the gel shown in fig. 2 .

carrying streptomycin and chloramphenicol resistance determinants hybridised with its parent plasmid (the two bands in fig. 3 , lane 1 . corresponding to the two leading bands in fig. 2, lane 1), with the plasmid from $E$. coli MS5, resistant to streptomycin only (fig. 3, lane 2) and with itself (fig. 3, lane 3). Similarly pMS7, which conferred resistance to ampicillin, hybridised with the parent plasmid (fig. 4, lane 1), with itself (fig. 4, lane 5) and with pBR322 which harbours a $\beta$-lactamase determinant. Neither pMS6 (conferring streptomycin and chloramphenicol resistance) nor pMS7 (conferring ampicillin resistance only) hybridised with the plasmid preparation from $E$. coli MS10, a tetracycline-resistant segregant obtained after subculturing an ApTc segregant in the presence of tetracycline. The original ApTc segregant retained both resistance markers when grown in the presence of ampicillin but tended to become osmotically fragile; growth in the presence of tetracycline readily resulted in the loss of the ampicillin-resistance marker. Spontaneous mini-plasmid formation occurred in these strains (fig. 2, lane 4) and these tetracycline-resistant segregants were osmotically stable. There was thus a very good concordance between the resistance phenotypes and the hybridisation profile, with little or no cross-hybridisation. This indicated that the mechanism of segregation of the antibiotic-resistance determinants was the deletion of various discrete lengths of plasmid DNA. Furthermore pMS7, which is in the same size range as pBR322. appeared to harbour a $\beta$-lactamase determinant homologous with the TEM $\beta$-lactamase gene of pBR322.

\section{Discussion}

The absence of hybridisation between segregant plasmids conferring different phenotypes seems to indicate a precise excision of resistance determinants rather than random deletions because in random deletions, rigid correspondence between hybridisation profile and phenotype would not be expected. That the deletions were indeed posttransformation events was indicated by the observation that the $E$. coli transformants, segregants as well as those which harboured all four resistance determinants, lost resistance determinants within a few generations unless an appropriate antibiotic pressure was applied, in contrast to wild-type $S$. typhimurium strain 993 which inherited all four resistance markers stably even in the absence of antibiotic pressure. This instability was also observed when the antibiotic-resistance-bearing plasmid from $S$. typhimurium strain 993 was transferred to $E$. coli $\mathrm{DH} 1$ by conjugation.

The instability of certain plasmids when transferred from Salmonella strains to $E$. coli has been observed previously (Anderson and Lewis, 1965). However the reverse observation, the instability of E. coli Inc FII plasmids such as R1, R6 and R100 in S. typhimurium (Watanabe et al., 1964) or Proteus species (Morris and Rownd, 1974) is better documented. In this case, recombination between the insertion sequences IS 1 flanking the resistance determinants was shown to cause its separation from the resistance-transfer factor (Chandler et al., 1977). A similar mechanism would account for the precise deletions taking place in $E$. coli transformed with $S$. typhimurium strain $993 \mathrm{R}$ factor. Watanabe et al. (1980 and 1982) isolated a mutant with a function dor of $S$. typhimurium LT2 which caused deletions of plasmids resulting from legitimate recombination between the homologous sequences flanking resistance determinant-bearing transposons, but had no effect on illegitimate deletions taking place as a result of the transposition phenomenon. This mutation left Rec functions intact as judged by resistance to UV radiation. If the observed segregations of plasmids from $S$. typhimurium strains 993 and 16408 were due to legitimate recombination events in $E$. coli similar to that directed by dor in $S$. typhimurium, either a plasmidencoded repressor for such recombination events effective in $S$. typhimurium but not in $E$. coli, or a difference in sensitivity of the plasmid to this function in the two species, may be postulated. There are reports which suggest that the plasmids R1-19 and R100 code for a repressor-like molecule that may interact with the $E$. coli gene product involved in recombination (Chernin and Ovadis, 1980). Furthermore, these plasmids are stable in $E$. coli and not in $S$. typhimurium, which has been 
attributed to the dor gene function of S. typhimurium (Watanabe et al., 1982).

Furthermore, because pMS6 ( $\mathrm{SmCp})$ and pMS7 (Ap) share no homology, and neither hybridises with pMS10 (Tc), multiple non-homologous replication origins may be present in the parent $S$. typhimurium plasmid; otherwise the shared replicator regions would have been expected to hybridise, assuming that these regions are not too small to be detected by hybridisation done under stringent conditions. Comparison of the mol, wts of the segregant plasmids conferring mutually exclusive phenotypes, pMS6 $\left(1 \cdot 7 \times 10^{6}\right)$, pMS7 $\left(2 \cdot 8 \times 10^{6}\right)$

\section{REFERENCES}

Anderson E S, Lewis M J 1965 Characterization of a transfer factor associated with drug resistance in Salmonella typhimurium. Nature 208:843-849.

Bolivar F, Backman K 1979 Plasmids of Escherichia coli as cloning vectors. In: Wu R (ed) Methods in enzymology, vol. 68, Academic Press, New York, pp 245-267.

Chandler M, Allet B, Gallay E, Boy de la Tour E, Caro L 1977 Involvement of IS 1 in the dissociation of the $\mathrm{r}$-determinant and RTF components of the plasmid R100.1. Molecular and General Genetics 153:289-295.

Chernin L S, Ovadis M I 1980 Plasmid control of recombination in E. coli K12. Molecular and General Genetics 179:399-407.

Christie A B 1980 Infectious diseases: epidemiology and clinical practice, 3rd edn. Churchill Livingstone, Edinburgh.

Clewell D B, Helinski D R 1970 Properties of a supercoiled deoxyribonucleic acid-protein complex and strand specificity of the relaxation event. Biochemistry 9:4428-4440.

Datta N, Dacey S, Hughes V, Knight S, Richards H, Williams G, Casewell M, Shannon K P 1980 Distribution of genes for trimethoprim and gentamicin resistance in bacteria and their plasmids in a general hospital. Journal of General Microbiology 118: 495-508.

Datta N, Richards H, Datta C 1981 Salmonella typhi in vivo acquires resistance to both chloramphenicol and co-trimoxazole. Lancet 1:1181-1183.

Gross R J, Ward L R, Threlfall E J, Cheasty T, Towe B 1983 Drug resistance among Escherichia coli strains isolated from cerebrospinal fluid. Journal of Hygiene 90:195-198. and pMS10 $\left(0.8 \times 10^{6}\right)$, with that of the parent $S$. typhimurium $\mathrm{R}$ factor plasmid $\left(5 \cdot 8 \times 10^{6}\right)$ appears to admit this possibility.

Our transformation experiments have simulated conditions which may prevail in the gut during the course of antibiotic therapy in that a selective pressure must select resistant bacteria resulting from the interspecies transfer of plasmids, but the stability of plasmids may vary in different host environments. Transposability of genes from one replicon to another may have provided one method by which this problem may be avoided.

Grüneberg R N, Bendall M J 1979 Hospital outbreak of trimethoprim resistance in pathogenic coliform bacteria. British Medical Journal 2: 7-9.

Maniatis T, Fritsch E F, Sambrook J 1982 Molecular cloning-a laboratory manual. Cold Spring Harbor Laboratory, NY.

Morris C F, Rownd R 1974 Transition of the R factor R12 in Proteus mirabilis. Journal of Bacteriology 118:867-879.

Sood L R, Basu S 1983 Epidemiological aspects of human salmonellosis in India- a review. Indian Journal of Microbiology 23: $251-263$.

Threlfall E J, Ward L R, Rowe B, Robins-Browne R 1982 Acquisition of resistance by Salmonella typhi in vivo: the importance of plasmid characterisation. Lancet 1:740.

Tomkins L S, Plorde J J, Falkow S 1980 Molecular analysis of Rfactors from multiresistant nosocomial isolates. Journal of Infectious Disease 141:625-636.

Watanabe H, Hashimoto H, Mitsuhashi S 1980 Salmonella typhimurium LT2 mutation affecting the deletion of resistance determinants on R plasmids. Journal of Bacteriology 142:145-152

Watanabe H, Mise K, Hashimoto H 1982 Recombination between two IS 1s flanking the r-determinant of R100-1: involvement of dor and recA gene functions in Salmonella typhimurium. Journal of Bacteriology 150:113-121.

Watanabe T, Ogata C, Sato S. 1964 Episome-mediated transfer of drug resistance in Enterobacteriaceae. viii. Six-drugresistance R factor. Journal of Bacteriology 88:922-928. 